\title{
Exploring new organisational forms in English higher education: a think piece
}

\author{
Ewan Ferlie $^{1}$ (D) - Susan Trenholm ${ }^{1}$
}

Published online: 28 April 2018

(C) The Author(s) 2018

\begin{abstract}
This 'think piece' explores whether new organisational forms are now appearing within English Higher Education (HE). The growth of non-public funding streams and the extension of Degree Awarding Powers to alternative providers might encourage such shifts. We suggested the conventional Private Limited Company is not in principle the only alternative to the publicly funded HE Institution. One consistent national policy driver in strategies of English public management reform has been support for third sector orientated providers which may have had effects in HE. Our empirical conclusions about present organisational change patterns in the sector are, however, decidedly mixed. There is substantial but rather conventional $\mathrm{M}$ and $\mathrm{A}$ activity between publicly funded $\mathrm{HE}$ providers which does not add to organisational variety. A small cluster of for profits has entered the English HE market, alongside another small cluster of non for profits. One site showed evidence of a slight move to a professional partnership form, mixed with private equity. Staff owned mutuals seemed very weakly developed. These novel organisations are as yet generally small scale, with a few exceptions. There was initial evidence found of larger scale developments in a novel and hybrid organisational space which combines: recently founded social enterprises, disruptive technological innovation, new forms of on line learning, often supported financially by large philanthropic foundations connected to the high tech sector. Large foundations may emerge as important influencers which complement shrinking government funding. The virtual university is another organisational change to explore further, especially given the rise of ICT dependent inter university and international consortia, but is not necessarily friendly to third sector ideas and forms. Finally, we explore the wider and more international implications of our early work on English HE for future research.
\end{abstract}

Keywords New organisational forms · Universities · Social enterprises · Staff mutuals · Professional partnerships $\cdot$ Philanthropic foundations $\cdot$ Digitalization

Ewan Ferlie

ewan.ferlie@kcl.ac.uk 


\section{Introduction}

This paper explores whether major organisational changes are emerging in English Higher Education. We investigate whether the sector is shifting from a previous planned, publicly funded and nationalised form and is now undergoing liberalisation and pluralization, thereby encouraging the emergence of novel provider types. Why might this question be worth enquiry?

Recent national policy changes in English HE include more non-public finance for Universities (including but going beyond much higher student fees) and decreased traditional public sources of revenue. There are now many high fee paying overseas students in English HE, not funded by the government, reflecting England's wider status as an open and globalised economy. Indeed, nine of the top 20 HEIs globally with the highest percentage of international students are in England (THE 2017). English HEIs are engaged in wider globalisation processes, participating in many international inter University groupings and alliances. New Information and Communication Technologies (ICTs) are rapidly digitalizing administrative and academic work processes, creating more virtualised and cross border academic networks.

Specifically, the English government's policy of extending Degree Awarding Powers (DAPs) to 'alternative providers' seeks to stimulate new market entrants and disrupt incumbent providers. DAP led liberalisation was promoted further by the recent 2017 Higher Education and Research Act with support for market entry by 'challenger' institutions.

We here ask: does current (admittedly limited) evidence suggest these national level policy forces are creating greater organisational variety at HEI level?

Pluralization would mark a major change to the previous highly institutionalised pattern: Mulgan and Joshi (2016) recently critiqued the lack of 'serious strategic innovation' in UK HE and also the weak HE sectoral literature on this important theme. We see these ideas as reflecting support for the influential model of 'disruptive innovation' (e.g. Christensen and Overdorf 2000, influenced by Schumpeter 1950). Such disruptive innovation is often driven by new technologies, notably ICTs. The HE sector is, Mulgan and Joshi (2016) argue, lagging and 'off the pace'. But is their view too pessimistic? Is there, by contrast, recent evidence of new organisational forms emerging? Critics of this 'disruptive innovation' view could also argue radical innovation-perhaps of a risky and untried form - could weaken institutional stability and resilience, thereby threatening the educational experience of large cohorts of students.

One view of likely organisational changes is that the declining publicly funded HEI would simply be replaced by the private sector Private Limited Company (PLC) as a dominant provider type, accountable primarily to its shareholders, perhaps short termist and mainly interested in extracting dividends. Universities could be bought and sold in the marketplace like a bank or car firm. Indeed, some policy commentators call for more privately owned HEIs (Fazackerley and Chant 2009).

Nor would privately owned HEIs necessarily take the simple form of a UK headquartered PLC, subject to well-developed corporate governance requirements, including being registered and filing transparent reports at Companies House in London. In an open economy, corporate groups could quickly form in HE (as in the banking and retail sectors) to deliver provision in England but remain headquartered in a lower tax jurisdiction for entirely legal tax minimization reasons. 
But are 'third sector' and alternative organisational forms emerging which cross this crude state/market binary? Anheier (2006) suggests that the third or non-profit sector is a major economic and social force internationally, reflecting growing scepticism about both state and market led solutions to social problems. Non-profits at their best should be: trustworthy, orientated to quality as well as cost, and adept at encouraging volunteering and participation from below. As such, they are a key element of wider 'civil society'.

Non-profits' governance structures are distinctive (Cornforth 2014), taking the form of a Board of Trustees elected by all members at an Annual General Meeting (AGM). This form is different both from the Board of Directors accountable to shareholders in a PLC or a Board appointed by government and facing 'upwards' to ministers as in many UK public agencies. We here ask whether third sector orientated organisational forms are now emerging in English HE given a policy of pluralization.

This paper will briefly review some key academic literature on new organisational forms, both generally and then in the HE sector. We then highlight a sustained policy push from successive UK governments to promote alternative provider forms. We would expect at first glance these wider reform ideas to have had application in the HE sector, as in other public services. We will outline our approach and methods in writing this 'think piece'.

We give brief vignettes of interesting current organisational developments in the English HE sector, and also consider their limitations. The evidence so far available about such organisational pluralization is weak and decidedly mixed. We finally outline an agenda for further empirically orientated research on the evolution of the HEI as an organisation and to consider implications at a more international level.

\section{Methods and approach}

We here build on our recent rapid literature review (Ferlie and Trenholm 2017) which explored contemporary organisational changes in UK HE. We took a particular interest at that stage in increasing Mergers and Acquisition ( $\mathrm{M}$ and $\mathrm{A}$ ) activity and we began to explore the idea of new organisational forms. This review was based on a structured literature search of a set of key general management and HE orientated academic journals. We also searched for UK public management reform and HE policy documents as well as on organisational websites to capture institutions' self descriptions (we recognise there may be presentation of an institutional self in these accounts but they provide basic factual information and the discourse employed may itself be revealing). We consulted relevant HEIs' filing histories with Companies' House and the Charity Commission. We decided to restrict the current paper to English HE given the constitutional arrangement that Scotland, Wales and Northern Ireland all now have devolved powers over HE policy and different policy trajectories may be emerging there.

We (briefly) suggested that some intriguing experiments with new organisational forms in HE may be emerging. We explore this initial observation in much greater depth here, undertaking further investigation. We have brought in academic literature on new organisational forms as a more explicit theoretical framing. We reviewed UK public management reform ideas and texts on the so called 'Big Society' reform narrative further. We have here developed our vignettes further. The present paper is a 'think piece' designed to stimulate imaginative thought; to link the HE sector with wider academic and public policy literatures and to build an agenda for future empirical research. 


\section{From isomorphism to deinstitutionalization in the English HE sector?}

We start with some academic literature. One influential theoretical approach to the study of embedded organisational fields (here the HE field) reflects the neo institutionalist tradition. This school (Di Maggio and Powell 1983; Greenwood et al. 2008) assumes such fields are driven by legitimacy pressures (given weakly developed markets) which then lead to strong mimetic processes or 'follow the leader' bandwagons. Imitation of fashion setters is seen as the sincerest form of organisational flattery and as highly likely to occur. Over time, fields become isomorphic and lack organisational variety. For example, scholars of the expanding Business School sector evident within HE (Wilson and McKiernan 2011) have suggested that it faces strong mimetic pressures. These pressures may be amplified by public league tables, accreditors, specialist media, a globalised degree (the MBA), national peak associations and a tendency to copy the high status American Schools. Many of these isomorphic forces may also be evident in wider HE systems, albeit to a less pronounced degree (see Marginson 2002 on isomorphism in Australian HE). In still substantially publicly funded HE systems as in England, a sectoral wide steer from government agencies (HEFCE, now rebadged as the more high profile Office for Students) remains important.

We here however explore an alternative scholarly viewpoint, namely the possible deinstitutionalisation of the English HE sector. There is a small but interesting stream of general academic literature on the emergence of new organisational forms. Organisational innovations are here seen as more likely under certain economic and social conditions which provoke the rare 'deinstutionalization' (Oliver 1992) of a once mature sectoral field, encouraging radical organisational innovations. In such deinstitutionalization, novel forces, actors and beliefs disturb a narrow range of previously taken for granted organising recipes across the sectoral field. Underpinning values and bases of legitimacy become contested as organisational fields become less homogenous.

The English HE sector may possibly now be experiencing such 'deinstitutionalization' (Oliver 1992). Various external policy jolts combine: a rapid retreat of public funding, increasing competition for high fee paying students and growing alternative income streams (e.g. technology transfer; alumni). There is wider globalisation, reflecting the exceptional openness of (and financial dependence on) the system to high fee overseas students. New ICTs may produce 'creative destruction' (Schumpeter 1950) in HE, as elsewhere (e.g. radically new business models in retail and banking). These discontinuous changes may stimulate alternative responses from HE organisations (Ilinitch et al. 1996), sensing of high environmental uncertainty but doing so in different ways and offering alternative 'solutions'.

'Disruptive innovation' (Christensen and Overdorf 2000) theory suggests that incumbents (in any sector) may be brutally and quickly displaced by challengers with radically different business models. There appears currently to be a policy discourse favouring disruption innovation and 'challenger institutions' in the UK HE field. This literature suggests challengers may provide acceptable rather than outstanding levels of quality but operate with lower costs and may be attractive to traditionally under served populations that cannot afford elite products. ICT 'push' is further cited as potentiating discontinuous change (Ilinitch et al. 1996) in private sector settings.

Romanelli (1991) explored the developing literature on new organisational forms, highlighting three alternative schools. The first school was termed 'organisational genetics' where there are no 'guiding hands', but where difficult to predict micro change processes emerge from below. It is suggested that two other schools are of more interest here as they 
combine a concern for wider organisational context (including the national political economy) and organisational capability.

The second school is termed 'environmental conditioning', where variation is more constrained: environmental conditions produce particular organisational forms. This theory indicates periods of 'creative destruction' (Schumpeter 1950), seen as a competitive process that creates new organisational forms in response to new technologies. Incumbents may be displaced and old organisational forms face extinction if they cannot keep up with the new basis of competition. However, there are no closures of failing English HEIs as yet (so how does a HEI go bankrupt?), although significant mergers and acquisitions activity is evident. Between 1995/96 and 2016/17, our search suggests there were 49 UK HEI mergers, of which 35 were in England (HESA 2018).

In organisational 'imprinting' (Stinchcombe 1965), new organisational forms reflect historically specific founding conditions. Radical political and ideological change can act as an important historical breakpoint, particularly so within publicly funded organisations. Specifically, we suggest the new Thatcherite political economy of the 1980s, and also the Blairite era of 1997-2010, may have triggered long term organisational changes in English HEIs, as in other English public services organisations.

A third theoretical approach is 'organisational speciation'. Some organisations are better at becoming 'organization creating organizations', reflecting their greater capacity to engage in significant organisational innovation, perhaps on a repeated basis. There are similarities here with the Resource Based View (RBV) (Penrose 2009; Wernerfelt 1984) of the firm in strategic management, whereby it is argued that firms (or indeed organisations) vary in their core capabilities, such as their ability to sense and use information, to learn and to change. Nor should the role of agency and leadership be neglected: a visionary founder or founding group may imprint an organisation with long-term direction and even underlying culture and ideology (Pettigrew 1979).

\section{Some HE orientated literature on new organisational forms}

The organisational forms thread is rather under explored in the HE sectoral literature, although there is some work. For example, Clark (1998) characterises a subgroup of 'entrepreneurial' universities (e.g. Warwick in England), where the third mission of knowledge transfer and commercialization moved centre stage alongside traditional missions of teaching and research, associated with wider institutional changes. Marginson and Considine (2000) explore the enterprise university specifically within the Australian system. There is here typically an increased power of senior management (e.g. appointment of Executive Deans) and weaker traditional collegiality. Deem et al. (2007) investigated the impact of managerializing or New Public Management (NPM) inspired reforms in UK HEIs. More powerful (and better paid) senior managerial roles emerged, often filled by hybrid academic managers, that is senior academics who take on a second and more managerial career.

This literature stream is consistent with imprinting theory as it suggests that 1980 s and 1990s radical public management reform challenged the old archetype of the professionalised bureaucracy. The central trajectory since then has been for UK Universities to become both more entrepreneurial/market minded and (paradoxically) more managed internally. 
Our literature review found two other interesting papers exploring current HE organisational changes. It is suggested that the traditional university as a vertically integrated, physically present and hierarchical organisation may be shifting to a more 'heterarchical' (Jacob and Hellström 2003) and virtualised network of allied HE or research organisations. They define a 'heterarchy' as characterised by: (p62) 'minimal hierarchy and by organizational heterogeneity, with relative autonomy with respect to delegated goal setting and opportunity scanning, but with integration with respect to internal cooperation and shared culture.' Speed, flexibility and innovation become more important than traditional search for scale and predictability (Jacob and Hellström 2003), with scaling, in particular, not an issue for virtualised organisations or alliances which may be "global" even at launch. There are however significant organisational challenges in managing such virtualised networks, including (p56) 'the definition of core competences, the retention of absorptive capacity, the management of alliances and the ability to manage knowledge to promote the creation of new organizational capabilities.'

Is disruptive new technology a motor of significant organisational change in virtual HEIs? Jacob and Hellström (2003, pp55) cite the example of Surrey European Management School: 'where students are given a pre configured lap top computer with study aids, access to document databases and virtual seminar rooms and are then left to fulfil course requirements by taking modules at a selection of international partner schools around Europe. Students pick the location (supplier) best suited to the courses they require and to other commitments they may have'.

Lewis et al. 2005 examined possible moves to a 'network university' in five case studies of Australian Universities. They noted the influential 'network society' (Castells 1996) narrative of organisational change in a knowledge based economy, where new ICTs encourage radically new post bureaucratic, 'post Fordist' and network based organising. In contradiction to the neo Marxist deskilling hypothesis, workers in these settings become more knowledgeable, more broadly skilled and may act as self motivated 'connectors'. Castells' (1996) analysis is, however, centred more on private firms than publicly funded settings (such as Australian Universities).

Their case study work found different organisational currents coexisted: on the one hand, there were more new and ICT-facilitated modes of teaching and learning alongside the growth of collaboratives within and beyond universities. However, old NPM practices also seemed strongly embedded. They concluded that the networked university remained as an ideal more than a norm: ICTs did not by themselves exert transformational organisational change but interacted with — and were influenced by - existing academic work settings.

\section{UK public management reform strategy supports third sector providers}

Paradoxically, one reason for the growth of alternative and third sector orientated organisational forms across the English public services - perhaps including the HE sectorhas been the national government's macro level public management reform strategy (Pollitt 2013). Such reform strategies have gone beyond a pure reliance on NPM ideas and have also included softer ideas around Network Governance (NG) (Newman 2001). Sustained support for third sector public orientated services provision was evident both under New Labour governments (1997-2010) and indeed in later Conservative led or Conservative only governments (2010 onwards). 
New Labour governments (1997-2010) supported third sector approaches in such reform. Their pioneering use of novel social enterprises and activated civil society politically enabled them both to go beyond old Labour's Statism but also the privatisation and NPM orientated reforms of earlier radical right Conservative governments (1979-1997) (Newman 2001, p144). New Labour's political discourse favoured goals of 'social inclusion', active citizenship and the involvement of civil society in public policy. Third sector organisations (Newman and Clarke 2009, pp 46-48) were now more favoured sites for closer partnership with government, as they linked to disadvantaged groups excluded from narrowly managerialized decision making during earlier NPM reforms.

Perhaps surprisingly, similar ideas were influential in Conservative leaning think tanks and political circles as they formulated their public services reform programme for a post New Labour government. Blond (2010's) post NPM critique, influential with David Cameron (Conservative Prime Minister in the 2010-2015 government) outlined the toxic effects of a dominant markets/management approach and advocated more active and self regulating professions and mutuals. These ideas potentiated a 'Big Society' proto reform narrative apparent around 2010. Of course, it is unclear whether it endured or was rather trumped by wider post 2010 austerity pressures and policies from the powerful Treasury.

Another scenario is that limited pockets of mutualising reform have somehow endured in some sectors, partly because it enables financially pressured public services providers to spin out functions (e.g. local government; community health services) to lower cost alternatives. We ask: have mutualising ideas had traction in the HE sector?

\section{Organisational changes in current English HE}

We move from reviewing academic and public policy literature to explore organisational changes empirically evident in English HE. There is firstly clearly a substantial amount of Mergers and Acquisitions ( $\mathrm{M}$ and $\mathrm{A}$ ) activity evident as smaller and pressured HEIs seek shelter with larger and stronger institutions. Some more strategic mergers are also apparent, motivated by regional economic development concerns, and a desire for a stronger, more competitive global presence (Goedegebuure 2012; Pruvot et al. 2015).

For example, the 2004 merger of the Victoria University of Manchester and the Manchester Institute of Science and Technology to create the University of Manchester, was championed politically and supported with 80 million GBP in state funding (Fazackerley and Chant 2009). The goal was for the new university to rank amongst the world's top universities, also contributing to the economy in the north of England. A merger with mainly regional significance, particularly from an economic development perspective, by contrast, created (in 2007) the University of Cumbria, also financially supported by government. So the motivation to merge varies. Williams (2017) argues the 2016 government-funded merger of the Open College of the Arts with the long-established University for the Creative Arts arose from a desire by the merging institutions to become large enough to gain full university status. The University for the Creative Arts website also cites its wish to access the Open College of the Arts' online education expertise and reach.

However, such $\mathrm{M}$ and A activity between two or more existing publicly funded HEIs is a conventional response which does not increase organisational variety. 


\section{The (gradual) emergence of alternative providers: for and not for profit}

More interestingly, some for profit providers have (slowly) been entering the sector, including BPP which was the first to get DAP status (2007) (http://www.bpp.com/bppuniversity/about/university-governance). Extending DAP powers to alternative providers started under New Labour governments but accelerated after 2010 under Conservative led or only governments. We ask: how substantial is this shift?

HEFCE's national register of HE providers in England lists 115 alternative providers (APs) with specific course designation. An estimated 53,000 students were on designated courses in 2015/16, concentrated in a high volume and vocationally orientated subject areas, notably business and management, law and the creative arts, all not requiring major capital investment (unlike the sciences). At course level, pluralization appears to be significant.

However, when we searched the HEFCE register for all entities that have: (i) DAPs, (ii) the title of university or university college, and (iii) institutional level specific course designation, only 7 entities emerged. (http://www.hefce.ac.uk/reg/register/search/Home/ByProperty, accessed 23 November 2017). A preliminary analysis of these 7 entities appears in Table 1.

Of the seven HEIs, four are classified by us as not for profits and three for profits. The classification was performed through an analysis of the content of the texts uncovered in the search (HEFCE regulatory reports and institutional websites) in terms of their ownership and governance structure: a for profit would be described as a Private Limited Company (PLC) or as a family business; a non-profit would be a registered charity or social enterprises which are often described as Community Interest Companies.

So the first point is that there is a not for profits cluster as well as more conventional for profits. For example, Buckingham pioneered independent provision (from the 1970s) and has continued as a not for profit. Its political and ideological coherence and its adherence to classical liberal principles is clear from its founding conditions, being strongly supported by Margaret Thatcher as Secretary of State for Education in the early 1970s. Its value commitment makes it somewhat of an ideological deviant within the wider English HE sector. It has achieved some growth and diversification since the 1970s but remains relatively small scale. Nor has it spawned a series of 'clones' but remains a one off experiment.

Regent's University in central London is an interesting non-profit which recently achieved growth and greater scope. The London Institute of Banking and Finance has a long history in its 'niche' sector and remains a registered charity, as does the University College of Estate Management.

Of the three for profit HEIs, the high volume BPP has long been for profit. Arden started off as a family business but later converted to for profit status. The originally non-profit College of Law later converted to for profit status, then renamed as the University of Law. There are international firms in this for profit cluster (e.g. Global University Systems which is headquartered in Amsterdam, Apollo in the case of BPP 2009-2017) and also now private equity investors (BPP, 2017) given recent acquisition activity.

So two HEIs have moved towards a PLC status but with no movement the other way. These HEIs are usually small and the range of subject areas restricted. Provider diversification has remained generally small scale (as yet) at the HEI level, although BPP is a high volume exception. 


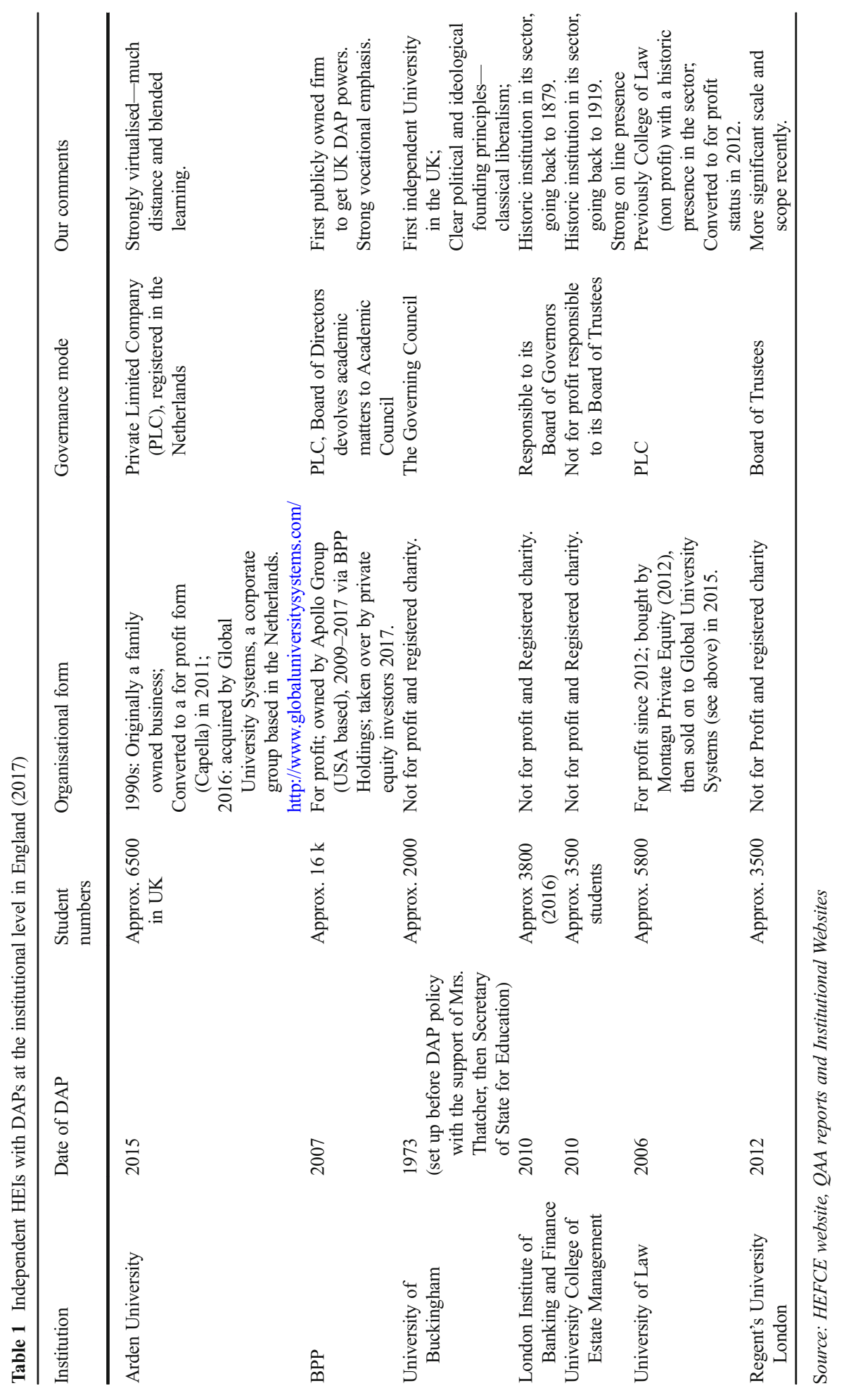




\section{Third sector friendly public services reform narrative: implications for the HE sector?}

We now explore whether third sector-based approaches to public services reform have had impact in the English HE sector.

\section{Staff owned mutuals}

A key idea in post 2010 UK reforms has been support for staff owned and mutualised organisations. A Mutuals Task Force was set up within the Cabinet Office in 2011 to promote the mutualisation agenda nationally. A 'mutual' was defined as: 'an organisation that has left the public sector which continues to provide public services (under contract) and in which employee control plays a significant role in its operation'. (https://www.gov. uk/government/publications/the-mutuals-taskforce-publications).

Current data indicate just over half (51\%) of public service mutuals operate as Community Interest Companies (CICs) in governance terms (CIPFA 2017). Most remain small scale, and 'scaling' up is a significant challenge (CIPFA 2017).

The limited current evidence suggests mutualisation has progressed faster in health and the culture and media sectors than in education. 110 public service mutuals are recognised by the UK government (https://www.gov.uk/guidance/introduction-to-public-service-mutuals. Accessed 25 January 2018), of which only $10 \%$ of a surveyed sample self-identified as working with the "education" sector. By contrast, $48 \%$ are within the health sector (CIPFA 2017).

$\mathrm{HE}$, in particular, appears as a lagging sector, with potentially slightly more activity in Further Education (FE) (https://www.gov.uk/government/uploads/system/uploads/attachment data/file/61777/Pipeline-of-Public-Service-Mutuals.pdf, accessed 3 December 2017). Within FE, there is a brief but intriguing reference in the Mutual Task Force's 2012 'pipeline' list to a project in Stockport FE College of governance reform to involve staff in the strategic direction of the college. The Stockport example is highlighted in case studies presented by the Learning and Skills Improvement Service (2012), along with a mutualisation programme undertaken by Birmingham Metropolitan College. However, did these attempts at mutualisation take real hold? Five or so years later, neither college's website mentions mutualisation, or significant staff involvement in college governance.

We conclude that so far staff mutualisation appears to have had a low impact in HE.

\section{Not for profits}

The not for profit form is long established in social policy sectors, including social housing and social care. It is an alternative to both market and hierarchical modes of governance, producing (at its ideal form): a collective clan-like culture, a strong mission and a relatively weak hierarchy. Volunteers produce an important source of unpaid labour for non-profits but may need to be motivated to retain their non paid engagement, partly by having the chance to influence the running of the organisation.

In governance terms, such organisations are usually accountable to a Board of Trustees elected at the AGM by members, rather than a Board of Directors accountable to shareholders, as in a PLC. 
Table 1 suggests that four non-profit HEIs currently have DAPs. Two are historic and 'niche' providers. Buckingham was founded in the 1970s as a classical liberal experiment. Interestingly, a significant HE non-profit is becoming apparent with a recent grant of DAPs: Regent's University London in central London is a not for profit provider awarding its own degrees (from 2012) and governed by a Board of Trustees. Its income stream overwhelmingly comes from tuition fees (Regent's University 2017) and it attracts many international students. Its educational offerings are mainly in non STEM subjects and job related (e.g. business studies, now extending into fashion and design). It currently has about 4000 FTE students so has developed some scale and scope but states it does not wish to massify (Regent's University 2017) further to keep a 'human touch'. It appears to be 'deglobalizing' and moving away from a historic American collaboration. A broadly positive report from a regulator (QAA 2016) noted that in governance terms there was a 19 member Board of Trustees, complemented by a managerial grouping around the Vice Chancellor and associated Directorate. While it is an intriguing experiment which should be followed further, Regents' University appears as yet to be a one off example.

\section{The professional partnership}

Another alternative form is the professional partnership which is both owned and managed by its partners, usually senior professionals, rather than by shareholders or by government. Senior managers and non-executives at Board level (or the Council in UK HE) are presumed to be weaker: rather power lies with the few professional partners. It is an oligarchy rather than a democracy as many junior professionals and non-professional staff have much less power.

Within the group of partners, the management style is often relatively collegial. The partners 'elect' a managing partner for a specific period of time but who then demits and goes back into the ranks. The managing partner would be expected to consult with other partners in major decisions. The partners' ability to secure fees would be seen as an important indicator of their performance.

The partnership form is well developed in other knowledge intensive and professionalised settings, including law (Empson and Chapman 2006) and primary health care (Sheaff et al. 2012), similarly located in the publicly funded sector. Sheaff et al. 2012 suggest that the primary care professional partnership form will prioritise service quality and a collegial working environment as core objectives as well as profit maximisation and productivity, so the form may at its best exert a broadening and humanising effect.

An interesting HE example is the New College of the Humanities (NCH) in central London, recently founded by the well-known philosopher A.C. Grayling and which admitted its first students in 2012. It remains a small scale provider with only about 140 students (QAA 2015), mainly in the liberal arts. As to be expected in such a recent foundation, it does not have DAP powers and its degrees are currently validated by other UK Universities (Swansea and Solent). https://www.nchlondon.ac.uk/faqs/. A recent QAA report was broadly positive (QAA 2015) about educational quality.

Its filing history in Companies House (Company number 07917776) suggests it is a private limited company with two shares: an ordinary share owned by Tertiary Education Services Ltd. and a 'golden share' owned by the Trust, as a charitable arm governed by its Trustees.

Tertiary Education Services Limited's filing history (Company number 07317195) suggests it is a private limited company. There are ten named directors, of whom two are senior academics. Its 2016 Annual Report indicates that some senior academics own shares in the 
business. These equity holdings are small compared with institutional or international personal investors, although the master of the college owns a more substantial holding. Resolutions of the company (October 2016) allow in principle for distribution of dividends to shareholders.

In sum, the records suggest that the New College for the Humanities is both a PLC and a charitable trust. PLC shareholders include some senior academic staff. While their equity holdings are small, this is an interesting experiment with an embryonic professional partnership form. A mixed model combining more conventional venture capital with some professional staff ownership may be more feasible in HE than a pure professional partnership form, given the large capital investment needed for a new university (the case of Circle in health care offers a similar mixed model).

\section{Social enterprises}

Social enterprises can be defined as mission driven organisations which seek to address unmet social needs, sometimes promoting radical and disruptive innovation (typically not favoured by cautious incumbents) and using new ICTs. There are examples to be found of novel and potentially disruptive approaches to on line learning provision in HE.

For example, the American based Peer2Peer University (P2PU) (founded in 2008) describes itself on its website https://www.p2pu.org/en/about/ as a non-profit organisation that promotes learning outside institutional walls and uses a virtual platform to facilitate face-toface, peer-led learning, often in public spaces such as libraries:

'Peer 2 Peer University (or simply P2PU) is a non-profit organisation that facilitates equitable learning beyond institutional walls. Founded in 2008 we have grown into a distributed community of educators, librarians, activists, policy-makers, and technologists. We train librarians and community leaders to facilitate learning in their neighbourhoods, develop and curate open educational resources and software, and champion related causes including open education, digital equity, and public libraries.

Their discourse thus displays a strong value base, championing learning activism and indeed activists. The vision further goes beyond simple ICT push to consider the underlying social and educational setting.

P2PU charges no tuition fees and its courses are not accredited. It has received funding from the Hewlett Foundation (an important initial funder) and the Shuttleworth Foundation which both support positive social change. It uses facilitated learning circles to supplement technology. In designing and leveraging open source education tools and resources, P2PU claims it offers a novel high-quality, low-cost, model for lifelong learning. Its emphasis on face to face social interaction and building a community of practice marks it out from standard Massive Open Online Courses (MOOCs).

The Khan Academy (https://www.khanacademy.org/) is an American social enterprise (founded in 2006) providing free online education globally through videos on You Tube and other media. It claims it operates with high volume and in various languages. It has attracted support and donations from such high profile non-profit organisations as Google, Tata Trusts, the Bill and Melinda Gates Foundation and the Carlos Slim Foundation which sought in particular to promote Spanish content. Such Foundations represent a significant source of its income (see below). It develops and delivers content in collaboration with major partners such NASA, MIT, and the Metropolitan Museum of Art. While it has corporate partners (e.g. AT\&T and Bank of America) listed on its website; USA federal government funding is not mentioned. 
These two cases suggest that major philanthropists and charitable foundations, especially from the high tech sector, might drive online based HE innovation.

A UK wide (rather than English) report suggests a drop between 2010 and 2012 in the number of social enterprises in the wider education sector. On the other hand, of 161 SMEs (small and medium sized enterprises) identified within UK education, 26\% (40/161) were social enterprises (Cabinet Office 2013). We could find no data on the prevalence of social enterprise(s) in the English or UK HE sectors; however, we do not believe any of these 40 social enterprises operate there. Rather, they seem to be found in the training sector, along with some business activity related to education consultancy (Private Correspondence 2018).

\section{Philanthropic foundations}

Anheier and Toepler (1999) have detected a growth of philanthropic foundations since the 1980 s, reflecting a wider reappraisal of the role of the state. Philanthropic foundations are seen as one way of mobilising civil society to counterbalance an over extended welfare state. Moreover, their rising endowment levels reflect the significant recent growth in the private fortunes of the richest individuals in society, some of whom create foundations which bear their name to pursue social purposes (e.g. Bill and Melinda Gates Foundation).

The Foundation movement was originally USA based with many large foundations being still based there. Some Foundations (including in the UK) have very substantial investment portfolios and income streams, representing for social enterprises a possibly less controlling alternative to government funding. We ask: as government retreats from HE; do the large Foundations fill the funding gap and if so, what are the implications?

For example, the Wellcome Trust is a major London based charitable funder operating across the health sector with a £21B investment portfolio in 2016 (https://wellcome.ac.uk/about-us/investments). It is a registered charity and governed by a board of Trustees. As well as its historic mission in funding bio medical research, it now invests more broadly in developing science education and runs an inspiring science' programme. Much funding is for science related work in schools, but Wellcome also funds some undergraduate related activity in science. It is also a major funder of capital investment in university science facilities.

Its scale and significance enable it to operate at a national policy making level. How might it influence the public policy field? Its charitable form may help nudge the HE sector towards a more public interest view of research which is less narrowly commercialised and patent driven and more aware of social purpose. Or do they pursue private interests and promote a closed policy agenda, arguably with less transparency than does old style parliamentary government and scrutiny?

\section{The virtualized university}

A final potential alternative form (though not necessarily third sector orientated) to be considered is the 'virtualised university'. New ICTs have been seen (Castells 1996) as leading to a novel network based form of the private firm, reflecting the centrality of information flows within a knowledge intensive economy. Organisations are less bureaucratic, hierarchical and inward looking; they rather become post bureaucratic, laterally based and 'connected' into key informational networks. While HEIs are key knowledge producers in such an economy, much of Castells' analysis relates to private firms. Less optimistically, Zuboff (1988) pointed to 
dystopian possibilities of new ICTs in creating pervasive electronic surveillance regimes within firms.

So is a 'Virtual University' emerging in HE which is changing conventional education provision and also creating a wider pattern of cross institutional organisation? Mulgan and Joshi (2016) recently focussed on the rise and implications of new learning technologies in HE, such as MOOCs and now SPOCs (Small Private Online Courses), seen as disruptive innovations. However, they did not explore organisational effects in any depth.

Current examples of distance and learning orientated HEIs include the for profit Arden University https://arden.ac.uk/ in the UK and Capella https://www.capella.edu/capellaexperience/about/ in the USA.

There are also online and international alliances between more conventional HEIs: for example, King's College London recently formed a research and education collaboration, PLuS Alliance, with Arizona State University and UNSW in Australia. This consortium is designed to develop cross border research programmes, develop and deliver related online educational programmes for governments and business, and facilitate research expertise on sustainability, global health, social justice and technology and innovation. There is a plan to award "cross-institutional degrees that are focused on global needs" (https://www.plusalliance. org/). We know little about how these ICT facilitated international alliances are governed.

\section{Concluding discussion and future research agenda}

This think piece explored whether alternative organisational forms may be emerging within traditionally highly institutionalised English HE. The growth of non-public funding streams and the extension of DAP to alternative providers might encourage such shifts. We suggested the conventional private sector PLC is not in principle the only alternative to the publicly funded HEI. The consistent national policy driver in English public management reform supporting third sector orientated providers may have had effects in HE.

Our empirical conclusions about present organisational change patterns are mixed. The substantial but conventional $\mathrm{M}$ and $\mathrm{A}$ activity between publicly funded $\mathrm{HE}$ providers does not add to organisational variety. A small cluster of for profits has entered the English HE market with DAP powers, alongside another small cluster of non-profits. One site showed evidence of a slight move to a professional partnership form, mixed with private equity. Mutuals seemed weakly developed. These novel organisations are as yet small scale, with a few exceptions (e.g. BPP).

Some initial evidence suggests larger scale developments in a novel and hybrid organisational space which combines: recently founded social enterprises, disruptive technological innovation, and new forms of online learning, often supported financially by large philanthropic foundations connected to the high tech sector. Large foundations may emerge as important influencers which complement shrinking government funding.

The virtual university is another theme to explore further, given the rise of ICT dependent inter university and international consortia, but is not necessarily friendly to third sector ideas and forms.

We need more empirically informed research (Mulgan and Joshi 2016) to identify local deviants and innovators (especially third sector friendly experiments) and explore whether currently small scale experiments endure and grow: are they resilient and can they be 'scaled up'? 
Other specific questions surfaced in our review include: will staff mutuals develop from their current marginal presence in HE? Will more professional partnership forms and social enterprises emerge? What are the organisational consequences of virtualization inside and between HEIs? What is the role of large philanthropic foundations in influencing HEIs and HE policy?

Future research should explore further interesting HE sites. Our initial search strategy did not capture some potentially interesting organisations, perhaps because they did not have university status.

Again, organisational change in the Business School sector may be (as yet) more advanced than in the rest of the sector and so interesting to study. For example, the well regarded, accredited and non-profit Ashridge Business School (which does not have university status so is not included in our list) seems to be globalising. It recently (2015) rebranded itself as Ashridge Executive Education, following an operational merger with the American based and also non profit Hult International Business School (http://www.hult.edu/en/executiveeducation/), with an extensive global network of partners. This case is interesting as a significantly scaled example of non-profit globalisation.

Secondly, the isomorphism/pluralism debate introduced here could usefully be explored further and empirically within emerging alternative provider settings. Are they really radically and enduringly different, including in their culture and internal power balance, as well as in educational offerings, or are they in the end subject to the same regulatory, market and normative ('student as customer') pressures as traditional providers?

One further limitation is that this early think piece is too England centric. Future international analysis of other high income countries with longer experience of a pluralised HE system would be useful. The HE reform ideas considered here could migrate from England to other jurisdictions, as England is an influential 'exporting' jurisdiction in wider public management reform historically (e.g. privatisation, executive agencies; managed networks, evidence based policy and more recently the Nudge Unit all created interest internationally). Tracing any policy transfer process in the HE sector would be of great interest.

Finally, our study found evidence of globally orientated actors including universities, university alliances, philanthropic foundations and HE orientated social enterprises in this space. How do these transnational entities (especially large HE orientated firms, social enterprises and philanthropic foundations) interact with traditionally nationally based $\mathrm{HE}$ policy regimes, governance and legal requirements?

Acknowledgements We acknowledge support from Professor Fiona Ross and the Leadership Foundation for Higher Education (LFHE) in commissioning an earlier literature review which suggested some early ideas which we have developed further here.

Open Access This article is distributed under the terms of the Creative Commons Attribution 4.0 International License (http://creativecommons.org/licenses/by/4.0/), which permits unrestricted use, distribution, and reproduction in any medium, provided you give appropriate credit to the original author(s) and the source, provide a link to the Creative Commons license, and indicate if changes were made.

\section{References}

Anheier, H. K. (2006). Nonprofit organizations: an introduction. Abingdon: Routledge.

Anheier, H. K., \& Toepler, S. (Eds.). (1999). Private funds, public purpose: Philanthropic foundations in international perspective. New York: Klewer Academic/Plenum Publishers. 
Blond, P. (2010). Red tory. London: Faber and Faber.

Castells, M. (1996). Rise of the network society. Oxford: Basil Blackwell.

Christensen, C. M., \& Overdorf, M. (2000). Meeting the challenge of disruptive change. Harvard Business Review, 78(2), 66-77.

CIPFA - Chartered Institute of Public Finance and Accountancy. (2017). Research into the public sector mutuals sector. London: CIPFA.

Clark, B. R. (1998). Creating entrepreneurial universities: organizational pathways of transformation. Issues in higher education. New York: Elsevier Science.

Cornforth, C. (2014). Non profit governance research: The need for innovative perspectives and approaches. In C. Cornforth \& W. Brown (Eds.), Non profit Governance, Chapter 1 (pp. 1-14). Abingdon: Routledge.

Deem, R., Hillyard, S., \& Reed, M. (2007). Knowledge, higher education, and the new managerialism: The changing management of UK universities. Oxford: Oxford University Press.

Di Maggio, P. J., \& Powell, W. W. (1983). The iron cage revisited: institutional isomorphism and collective rationality in organizational fields. American Sociological Review, 48, 147-160.

Empson, L., \& Chapman, C. (2006). Partnership versus corporation: implications of alternative governance for managerial authority and organizational priorities in professional service firms. Research in the Sociology of Organizations, 24, 145-176.

Fazackerley, A., \& Chant, J. (2009). Sink or swim? Facing up to failing universities. In Policy exchange, research note April. London: Policy Exchange.

Ferlie, E., \& Trenholm, S. (2017). The impact of mergers, acquisitions and collaborations in HE and other knowledge based sectors - a rapid review of the literature. London: Leadership Foundation for Higher Education.

Goedegebuure, L. (2012). Mergers and more: the changing tertiary education landscape in the 21st century. Norway: University of Oslo.

Greenwood, R., Oliver, C., Sahlin, K., \& Suddaby, R. (2008). Introduction. In R. Greenwood, C. Oliver, K. Sahlin, \& R. Suddaby (Eds.), The sage handbook of organizational institutionalism (pp. 1-46). London: Sage.

HESA, 2018. https://www.hesa.ac.uk/support/providers/mergers-changes (accessed on 23 Jan 2018).

Ilinitch, A. Y., D'Aveni, R. A., \& Lewin, A. Y. (1996). New organizational forms and strategies for managing in hyper competitive environments. Organization Science, 7(3), 211-220.

Jacob, M., \& Hellström, T. (2003). Organising the academy: new organisational forms and the future of the university. Higher Education Quarterly, 57(1), 48-66.

Learning and Skills Improvement Service (2012). Emerging models of delivery across the FE and skills sector: case studies. Publication reference: LSIS2012-12C, available at www.lsis.org.uk

Lewis, T., Marginson, S., \& Snyder, I. (2005). The network university? Technology, culture and organisational complexity in contemporary higher education. Higher Education Quarterly, 59(1), 56-75.

Marginson, S. (2002). Nation-building universities in a global environment: the case of Australia. Higher Education, 43(3), 409-428.

Marginson, S., \& Considine, M. (2000). The enterprise university: power, governance and reinvention in Australia. Cambridge: Cambridge University Press.

Mulgan, G., \& Joshi, R. (2016) Clicks and Mortarboards: How Can Higher Education Make the Most of Digital Technology?, London: NESTA https://www.nesta.org.uk/sites/default/files/higher_education_and_ technology_nov16_.pdf accessed 12 Nov 2017.

Newman, J. (2001). Modernizing governance. London: Sage.

Newman, J., \& Clarke, J. (2009). Publics, politics and power. London: Sage.

Oliver, C. (1992). The antecedents of deinstitutionalization. Organization Studies, 13(4), 563-588.

Penrose, E.T., 2009. The Theory of the Growth of the Firm. Oxford: Oxford University press (reprint).

Pettigrew, A. M. (1979). On studying organizational cultures. Administrative Science Quarterly, 24(4), 570-581.

Pollitt, C. (2013). The evolving narratives of public management reform: 40 years of reform white papers in the UK. Public Management Review, 15(6), 899-922.

Private Correspondence (2018). Email correspondence between Susan Trenholm and Social Enterprise UK.

Pruvot, E. B., Estermann, T., \& Mason, P. (2015). DEFINE thematic report: University mergers in Europe. Brussels: European University Association.

Quality Assurance Agency. (2015). Higher education review (plus) of tertiary education services Ltd trading as the New University of the Humanities. Gloucester: QAA.

Quality Assurance Agency. (2016) Higher Education Review (Alternative Providers): Regent's University London, Gloucester: QAA. http://www.qaa.ac.uk/en/ReviewsAndReports/Documents/Regent\%27s\%20 University\%20London/Regent\%27s-University-London-HER-AP-16.pdf, retrieved $17^{\text {th }}$ November 2017.

Regent's University London. (2017). Regent's annual review, 2015-2016, London: Regent's University. https://issuu.com/regentscollege/docs/annual_review_2015-16 (Accessed 23 Jan 2018). 
Romanelli, E. (1991). The evolution of new organizational forms. Annual Review of Sociology, 17(1), 79-103. Schumpeter, J. (1950). Capitalism, socialism and democracy. New York: Harper and Row.

Sheaff, R., Child, S., Schofield, J., Pickard, S., \& Mannion, R. (2012). Understanding professional partnerships and non-hierarchical organisations. London: NIHR-SDO.

Stinchcombe, A. L. (1965). Organizations and social structure. In J. G. March (Ed.), Handbook of Organizations (pp. 142-163). Chicago: Rand McNally.

THE (2017). https://www.timeshighereducation.com/student/best-universities/international-student-table-2017top-200-universities. Accessed 23 Jan 2018.

The Cabinet Office (2013). Social enterprise: market trends, based upon the BIS small business survey 2012. URN/xxx12. London: The Cabinet Office.

Wernerfelt, B. (1984). A resource-based view of the firm. Strategic Management Journal, 5(2), 171-180.

Williams, J. (2017). Collaboration, alliance, and merger among higher education institutions. In OECD education working paper 160. Paris: OECD.

Wilson, D. C., \& McKiernan, P. (2011). Global mimicry: putting strategic choice back on the B school agenda. British Journal of Management, 22(3), 457-469.

Zuboff, S. (1988). In the age of the smart machine: The future of work and power. New York: Basic books. 